\title{
Effects of dietary supplementation of glucose oxidase, catalase, or both on reproductive performance, oxidative stress, fecal microflora and apoptosis in multiparous sows
}

\author{
Xiaojiao Sun ${ }^{1,2}$, Longguo Piao ${ }^{2}$, Haifeng Jin², K. Margarette C. Nogoy ${ }^{3}$, Junfang Zhang ${ }^{1}$, \\ Bin Sun ${ }^{1}$, Yi Jin ${ }^{1}$, Dong Hoon Lee ${ }^{3}$, Seong-Ho Choi ${ }^{4}$, Stephen B Smith ${ }^{5}$, and Xiangzi Li ${ }^{1}$,*
}

\footnotetext{
* Corresponding Author: Xiangzi Li

Tel: +86-433-2435628, Fax: +86-433-2435628,

E-mail: Ixz@ybu.edu.cn

${ }^{1}$ Department of Animal Science, Yanbian University, Yanji 133002, China

${ }^{2}$ CJ Cheiljedang feed (China) R\&D center,

Shenyang, Liaoning, 110000, China

${ }^{3}$ Department of Biosystems Engineering,

Chungbuk National University, Cheongju

28644, Korea

${ }^{4}$ Department of Animal Science, Chungbuk

National University, Cheongju 28644, Korea

${ }^{5}$ Department of Animal Science, Texas A\&M

University, College Station, TX 77843-2471,

USA
}

\section{ORCID}

Xiaojiao Sun

https://orcid.org/0000-0001-8157-5364 Longguo Piao

https://orcid.org/0000-0002-7927-3719 Haifeng Jin

https://orcid.org/0000-0002-3177-600X

K. Margarette C. Nogoy

https://orcid.org/0000-0002-0958-7632

Junfang Zhang

https://orcid.org/0000-0002-4679-3857 Bin Sun

https://orcid.org/0000-0001-7138-9517

Yi Jin

https://orcid org/0000-0002-2241-4285

Dong Hoon Lee

https://orcid.org/0000-0001-7839-3201 Seong-Ho Choi

https://orcid.org/0000-0001-8869-0218

Stephen B Smith

https://orcid.org/0000-0002-2779-8281

Xiangzi Li

https://orcid.org/0000-0002-9993-5361

Submitted Dec 14, 2020; Revised Mar 13, 2021; Accepted May 24, 2021
Objective: The objective of this experiment was to investigate the effect of dietary glucose oxidase (GOD), catalase (CAT), or both supplementation on reproductive performance, oxidative stress, and apoptosis in sows.

Methods: A total of 104 multiparous sows were randomly assigned to four groups $(\mathrm{n}=26)$ with each group given a basal diet, basal diet plus GOD at $60 \mathrm{U} / \mathrm{kg}$, basal diet plus CAT at $75 \mathrm{U} / \mathrm{kg}$, and basal diet plus GOD at $60 \mathrm{U} / \mathrm{kg}$ and CAT at $75 \mathrm{U} / \mathrm{kg}$. Sows were fed the experimental diets throughout gestation and lactation.

Results: Dietary GOD supplementation increased average daily feed intake of sows and litter weight at weaning $(\mathrm{p}<0.05)$. Dietary CAT supplementation reduced the duration of parturition, stillbirth, and piglet mortality and increased growth performance of weaned piglets $(p<0.05)$. Dietary GOD and CAT supplementation enhanced antioxidant enzyme activities and lessened oxidative stress product levels in plasma of sows and elevated antioxidant capacity of 14 -day milk and plasma in weaned piglets $(\mathrm{p}<0.05)$. Dietary GOD supplementation increased fecal Lactobacillus counts and reduced Escherichia coli counts of sows $(\mathrm{p}<0.05)$. Compared with the basal diet, the GOD diet reduced fecal Escherichia coli counts of sows, but the addition of CAT did not reduce Escherichia coli counts in the GOD diet. Dietary GOD and CAT supplementation reduced the apoptosis rate of the liver, endometrium, and ovarian granulosa cells in sows $(\mathrm{p}<0.05)$. In the liver, uterus, and ovary of sows, the mRNA expression of caspase- 3 and caspase- 9 was downregulated by dietary GOD and CAT supplementation $(\mathrm{p}<0.05)$.

Conclusion: Dietary GOD and CAT supplementation could improve the antioxidant capacity of sows and weaned piglets, and alleviate hepatic, ovarian and uterine apoptosis by weakening apoptosis-related gene expression. Glucose oxidase regulated fecal microflora of sows, but supplementation of CAT to GOD could weaken the inhibitory effect of GOD on fecal Escherichia coli.

Keywords: Apoptosis; Catalase; Fecal Microflora; Glucose Oxidase; Oxidative Stress; Sows

\section{INTRODUCTION}

Continuous genetic selection has led to modern sows producing larger litter sizes with each offspring being leaner and growing faster [1]. Consequently, the sows need to produce enough milk to meet the increasing demand for milk production in its fast-growing litter. With fetal growth accelerating and placental metabolism intensity rising in late pregnancy and lactation, the mater subsequently displays adaptive changes such as increasing uterine blood flow and rising glycerin, free fatty acid (FFA), and alanine contents in the blood [2], which means metabolism intensity of mater is improving. All of these lead to 
generating numerous endogenous reactive oxygen species (ROS). Excessive ROS reacts with proteins, lipids, DNA, and other organic macromolecules, and causes oxidative damage [3]. Besides, endogenous antioxidant enzyme activity is constantly declining with increasing parity [4], which cannot remove excess ROS timely. Therefore, it is hypothesized that supplementation of dietary antioxidants to multiparous sows could reduce oxidative stress, especially in late pregnancy and lactation.

Glucose oxidase (GOD) catalyzes $\beta$-D-glucose to produce hydrogen peroxide $\left(\mathrm{H}_{2} \mathrm{O}_{2}\right)$ and $\beta$-D-gluconolactone by molecular oxygen, and $\beta$-D-gluconolactone spontaneously hydrolyzes to gluconic acid. Studies have shown that GOD is frequently utilized for improving the growth performance and immune function of animals due to gluconic acid and $\mathrm{H}_{2} \mathrm{O}_{2}$ produced by GOD in the gut $[5,6]$. Gluconic acid can improve intestinal health status and $\mathrm{H}_{2} \mathrm{O}_{2}$ inhibits the growth of harmful bacteria $[7,8]$. Wu et al [9] reported that GOD improved the growth performance of broilers mainly by enhancing intestinal digestive function and the abundance of beneficial bacterium. Meanwhile, catalase (CAT), decomposes $\mathrm{H}_{2} \mathrm{O}_{2}$ into water $\left(\mathrm{H}_{2} \mathrm{O}\right)$ and oxygen $\left(\mathrm{O}_{2}\right)$, together with superoxide dismutase and glutathione peroxidase (GPx) constituting the enzyme defense system to scavenge ROS in vivo. For clinical analysis, CAT is associated with anti-aging, tumor pathogenesis, and imbalance of free radical metabolism [10]. In vivo results showed that continuous intravenous injection of exogenous CAT significantly enhanced plasma and lung CAT activities in rabbits [11]. Amini et al [12] reported that CAT $(100 \mu \mathrm{g} / \mathrm{mL})$ supplementation improved the activity of post-thawed sperm and reduced malondialdehyde (MDA) level in cock. Li et al $[13,14]$ also indicated that the addition of CAT $(2 \mathrm{~g} / \mathrm{kg}$ diet) could increase CAT and total superoxide dismutase (T-SOD) activities in plasma and reduce the level of proinflammatory cytokines in the intestinal mucosa of piglets. Additionally, when GOD catalyzes the oxidation of glucose, $\mathrm{H}_{2} \mathrm{O}_{2}$ inhibits the catalysis of GOD [15], but CAT decomposes $\mathrm{H}_{2} \mathrm{O}_{2}$ to ensure a continuous and smooth reaction. This suggests that the interaction between GOD and CAT possibly has a better effect, which is of great guiding significance for the combined use of GOD and CAT as feed additives.

Effects of the addition of CAT on the oxidative capacity in piglets [13] and GOD on growth performance of piglets [5] have been reported, but there is no relevant literature available on the influence of combined dietary GOD and CAT on the reproductive performance and antioxidant capacity of sows. Therefore, this study was designed to evaluate how dietary GOD and CAT levels affected reproductive performance, antioxidant capacity, fecal microflora, and apoptosis of sows.

\section{MATERIALS AND METHODS}

The experiment was conducted according to the Guideline for the Animal Care and Use Committee of Yanbian University.

\section{Experimental design}

A total of 104 multiparous sows (parity 4.6 \pm 0.25 , Yorkshirex Landrace) from CJ (Shenyang) Feed Co., Ltd. (Shenyang, Liaoning, China) were used in a $2 \times 2$ factorial treatment arrangement. The first-factorial level was GOD at 0 or $60 \mathrm{U} / \mathrm{kg}$ diet (Sunson Industry Group Co., Ltd., Beijing, China), and the second-factorial level was CAT at 0 or $75 \mathrm{U} / \mathrm{kg}$ diet (Shandong Chunxu Bio-Technology Co., Ltd., Jinan, China). Glucose oxidase and CAT were produced through fermentation by Penicillium notatum, and their activities were 200 $\mathrm{U} / \mathrm{g}$ and $50 \mathrm{U} / \mathrm{g}$, respectively. All sows were randomly assigned to receive 1 of 4 treatments $(n=26)$ and fed the experimental diets throughout gestation and lactation. The four treatments were as follows: basal diet, basal diet $+75 \mathrm{U}$ CAT $/ \mathrm{kg}$ diet, basal diet+60 U GOD/kg diet, basal diet+60 U GOD/kg diet+75 U CAT/kg diet. This experiment was conducted from July to December 2018.

\section{Diets and management}

The diets (Table 1) were formulated based on the recommendation of the NRC (2012). Sows were fed $2.0 \mathrm{~kg} / \mathrm{d}$ from days 1 to 28 of gestation, $2.5 \mathrm{~kg} / \mathrm{d}$ from days 28 to 84 of gestation, $3.0 \mathrm{~kg} / \mathrm{d}$ from days 84 to 110 of gestation, and $1.8 \mathrm{~kg} / \mathrm{d}$ from day 111 of gestation to farrowing. After farrowing, the diet amount was improved by adding $0.5 \mathrm{~kg} / \mathrm{d}$ until ad libitum feeding during lactation. Piglets were weaned after 21 days of farrowing. Sows with similar body condition and parity ( $\mathrm{n}$ $=5$ per treatment) were randomly selected and slaughtered at day 21 of lactation to obtain liver, ovary, and uterus for gene expression and apoptosis analyses. The tissue samples were divided into two parts, one was frozen at $-80^{\circ} \mathrm{C}$, and the other was used for the paraffin section. The sows culled during the experiment were shown in Table 2. The back-fat thickness of sows was measured by ultrasound (Renco Corporation, Minneapolis, MN, USA) at P 2 position (60 mm off the midline at the 10th rib) during mating, on day 108 of gestation, farrowing day, and weaning. The number of piglets, litter weight, and average body weight (BW) were recorded after farrowing (day 1 of lactation) and after weaning (day 21 of lactation). Cross-fostering within the treatment group was implemented after $24 \mathrm{~h}$ of farrowing to attain $11 \pm 1$ piglets per sow.

\section{Sampling}

The blood samples ( $10 \mathrm{~mL}, \mathrm{n}=6$ per treatment) from the sows were collected by jugular venipuncture at day 28,80 , 
Table 1. Composition of basal diets (as-fed basis)

\begin{tabular}{|c|c|c|}
\hline Item & Gestation & Lactation \\
\hline \multicolumn{3}{|l|}{ Ingredients (\%) } \\
\hline Corn & 50.29 & 57.90 \\
\hline Sugar beet pulp & 6.00 & - \\
\hline Wheat bran & 20.00 & 3.00 \\
\hline Wheat flour & - & 5.00 \\
\hline Corn germ meal & 5.00 & 4.00 \\
\hline Dried distillers grains with solubles & 6.00 & - \\
\hline Soybean meal, $43 \%$ crude protein & 8.05 & 22.94 \\
\hline Fish meal & - & 0.50 \\
\hline Soy oil & 1.00 & 2.50 \\
\hline L-Lys-HCl, 78.8\% & 0.37 & 0.33 \\
\hline DL-Methionine, 98\% & 0.01 & 0.030 \\
\hline Limestone & 1.50 & 1.50 \\
\hline Dicalcium phosphate & 0.18 & 0.60 \\
\hline Salt & 0.50 & 0.50 \\
\hline Choline chloride, $50 \%$ & 0.10 & 0.20 \\
\hline Premix & 1.00 & 1.00 \\
\hline Total & 100.00 & 100.00 \\
\hline \multicolumn{3}{|l|}{ Calculated composition (\%) } \\
\hline Net energy $(\mathrm{MJ} / \mathrm{kg})$ & 9.41 & 10.00 \\
\hline Crude protein & 14.50 & 17.50 \\
\hline Crude fiber & 6.01 & 4.41 \\
\hline Lysine & 0.60 & 0.85 \\
\hline Methionine & 0.21 & 0.27 \\
\hline Threonine & 0.39 & 0.61 \\
\hline Calcium & 0.85 & 1.00 \\
\hline Available phosphorus & 0.32 & 0.36 \\
\hline \multicolumn{3}{|c|}{$\begin{array}{l}\text { 1) Provided per kg diet: } 15 \mathrm{mg} \mathrm{Cu}\left(\mathrm{CuSO}_{4} \cdot 5 \mathrm{H}_{2} \mathrm{O}\right), 90 \mathrm{mg} \mathrm{Fe}\left(\mathrm{FeSO}_{4} \cdot \mathrm{H}_{2} \mathrm{O}\right) \text {, } \\
100 \mathrm{mg} \mathrm{Zn}\left(\mathrm{ZnSO}_{4} \cdot \mathrm{H}_{2} \mathrm{O}\right), 30 \mathrm{mg} \mathrm{Mn}\left(\mathrm{MnSO}_{4} \cdot \mathrm{H}_{2} \mathrm{O}\right), 0.5 \mathrm{mg} \mathrm{I}\left(\mathrm{Cal}_{2} \mathrm{O}_{6}\right), 0.3 \\
\mathrm{mg} \mathrm{Se}\left(\mathrm{Na}_{2} \mathrm{SeO}_{3}\right), 7,000 \mathrm{IU} \text { vitamin } \mathrm{A}, 4,000 \mathrm{IU} \text { vitamin } \mathrm{D}_{3}, 100 \mathrm{IU} \text { vitamin } \\
\mathrm{E}, 4 \mathrm{mg} \text { vitamin } \mathrm{K}_{3}, 4 \mathrm{mg} \text { Thiamin, } 10 \mathrm{mg} \text { riboflavin, } 7.5 \mathrm{mg} \text { vitamin } \mathrm{B}_{6} \text {, } \\
0.06 \mathrm{mg} \text { vitamin } \mathrm{B}_{12}, 45 \mathrm{mg} \mathrm{D} \text {-pantothenate, } 60 \mathrm{mg} \text { niacin, } 0.5 \mathrm{mg} \text { biotin, } \\
12 \mathrm{mg} \text { folic acid, xylanase } 10,500 \mathrm{U} \text {, glucanase } 600 \mathrm{U} \text {, cellulase } 90 \mathrm{U} \text {, } \\
\text { mannanase } 1,200 \mathrm{U} \text {, phytase } 3,000 \mathrm{FTU} \text {. }\end{array}$} \\
\hline
\end{tabular}

and 108 of gestation (G28, G80, and G108, respectively), and day 1 and 14 of lactation (L1 and L14, respectively). The blood samples ( $5 \mathrm{~mL}, \mathrm{n}=6$ per treatment) from the piglets were collected by jugular venipuncture at birth and weaning. Plasma samples anti-coagulated with sodium heparin were obtained by centrifugation at $3,000 \times \mathrm{g}, 4^{\circ} \mathrm{C}$ for $15 \mathrm{~min}$, and stored at $-80^{\circ} \mathrm{C}$. Colostrum and $14-\mathrm{d}$ milk ( $\mathrm{n}=6$ per treatment) were obtained by hand-expression according to the method of Tan et al [16]. The fecal samples of sows ( $n=6$ per treatment) were collected at G28, G108, and L14.

\section{Evaluation of antioxidant capacity}

Antioxidant enzyme activities were analyzed in plasma and milk by commercially available kits (Nanjing Jiancheng Bioengineering Institute, Nanjing, China), including total antioxidant capacity (TAC), T-SOD, CAT, and GPx. The detection methods were reported by Meng et al [17]. Oxidative stress products including MDA, thiobarbituric acid reactive substances (TBARS), 8-hydroxy-deoxyguanosine (8-OHdG), and ROS in plasma or milk were measured by commercially available kits (Nanjing Jiancheng Bioengineering Institute, China), based on the methods of Zhao et al [18] and Tan et al [16].

\section{Quantification of microbial population}

After bacterial DNA was extracted from feces, the standard curve was established through quantitative real-time polymerase chain reaction (PCR; Applied Biosystems, Foster City, CA, USA) with specific primers (Table 3) as the method of Tan et al [16]. The microbial DNA was diluted 10-fold for quantitative analysis. All values were expressed as colonyforming unit (cfu) per gram of wet feces $\left(\log _{10} \mathrm{cfu} / \mathrm{g}\right)$.

\section{Terminal deoxyribonucleotide transferase-mediated dUTP nick-end labeling assay}

The apoptosis of the liver, uterus, and ovary in sows was detected by the transferase-mediated dUTP nick-end labeling (TUNEL) apoptosis detection kit (KGA7072; Jiangsu KeyGEN Bio-tech Co., Ltd, Nanjing, China) as the instructions. Under the action of terminal deoxynucleotidyl transferase enzyme, fluorescein isothiocyanate-labeled $5^{\prime}$-triphosphate (dUTP) was inserted into the $3^{\prime}-\mathrm{OH}$ ends of the broken DNA in apoptotic cells. The chromogenic reaction was observed under a fluorescence microscope (Jingtong Instrument Co., Ltd, Suzhou, China). The nuclei showed blue fluorescence through 4',6-diamidine-2-phenylindole staining, while apoptotic cells presented green fluorescence via TUNEL reaction mixture staining. Five fields (magnification, 400x) were ran-

Table 2. Number of sows in different periods of experiment

\begin{tabular}{|c|c|c|c|c|}
\hline \multirow{2}{*}{ Item } & \multicolumn{2}{|c|}{$0 \mathrm{U} / \mathrm{kg}$ GOD } & \multicolumn{2}{|c|}{$60 \mathrm{U} / \mathrm{kg} \mathrm{GOD}$} \\
\hline & $0 \mathrm{U} / \mathrm{kg}$ CAT & $75 \mathrm{U} / \mathrm{kg}$ CAT & $0 \mathrm{U} / \mathrm{kg}$ CAT & 75 U/kg CAT \\
\hline Breeding & 26 & 26 & 26 & 26 \\
\hline Culled during gestation ${ }^{1)}$ & 2 & 1 & 2 & 1 \\
\hline Parturition & 24 & 25 & 24 & 25 \\
\hline Culled during lactation ${ }^{1)}$ & 2 & 0 & 1 & 1 \\
\hline Weaning & 22 & 25 & 23 & 24 \\
\hline
\end{tabular}

GOD, glucose oxidase; CAT, catalase.

1) The culled sows refer to ill, metritis, reproductive failure, etc. 
Table 3. Specific primers used for quantitative real-time polymerase chain reaction

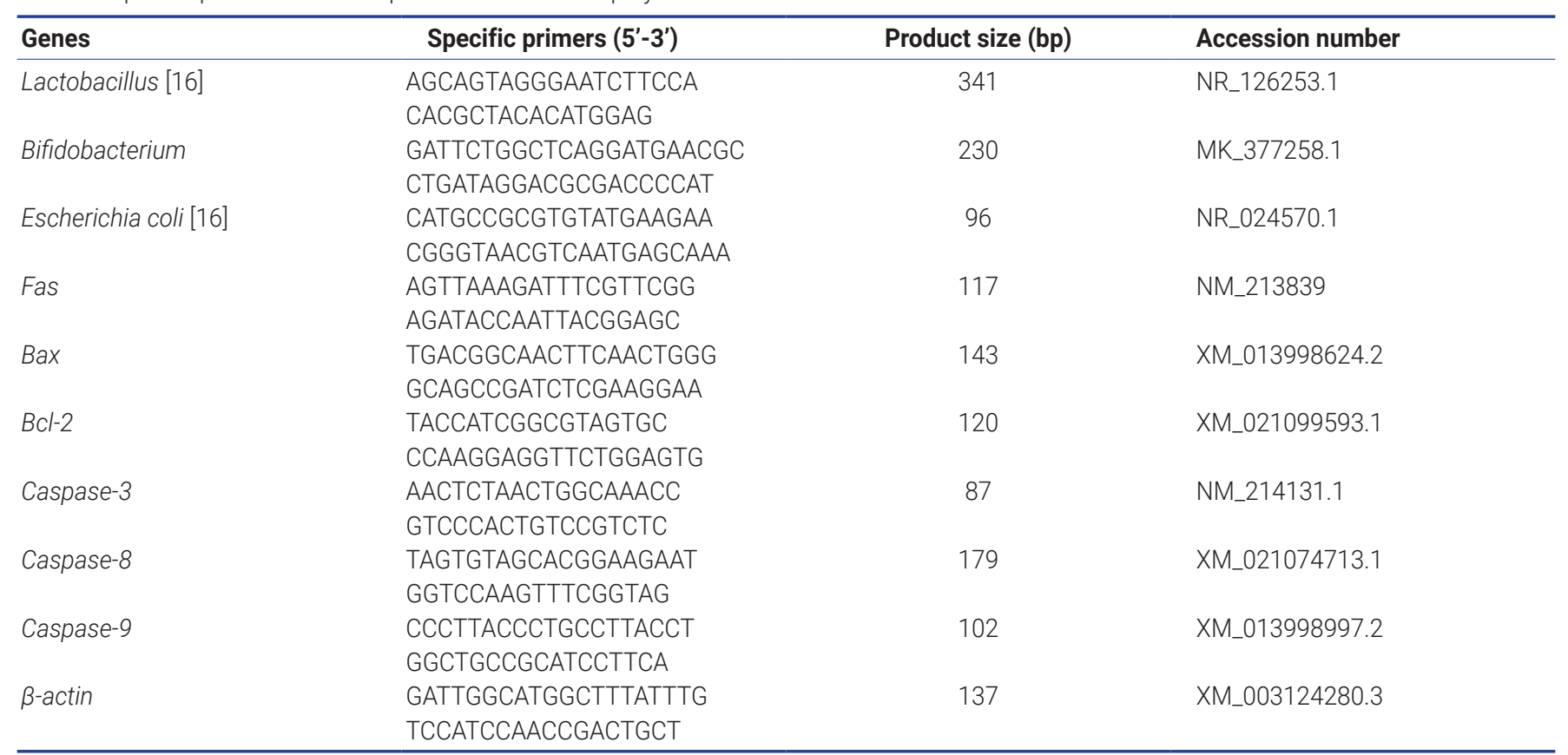

domly selected from each section, and the number of cells and apoptotic cells in each field were counted. The apoptotic rate was calculated.

\section{RNA extraction and real-time polymerase chain reaction}

Total RNA was isolated from the liver, uterus, and ovary using TRIzol reagent (15596018; Invitrogen, Carlsbad, CA, USA). Complementary DNA synthesis was carried out with PrimeScript RT Reagent Kits (RR036A; Takara, Dalian, China) as per the instructions of the manufacturer. The specific primers in Table 3 were used to amplify target genes using $2 \mu \mathrm{L}$ of the first-strand cDNA as the template in a $12.5 \mu \mathrm{L}$ SYBR greenbased quantitative real-time PCR reaction performed as follows: $95^{\circ} \mathrm{C}$ for $30 \mathrm{~s}, 40$ cycles at $95^{\circ} \mathrm{C}$ for $5 \mathrm{~s}$ and $60^{\circ} \mathrm{C}$ for $30 \mathrm{~s}$ with a melting curve from $60^{\circ} \mathrm{C}$ to $95^{\circ} \mathrm{C}$. $\beta$-Actin was served as a housekeeping gene to normalize gene expression levels in each sample. Relative expression was calculated using the $2^{-\Delta \Delta \mathrm{Ct}}$ method.

\section{Statistical analysis}

Data were analyzed by 2-way analysis of variance using the General Linear Model procedure of SPSS 20.0 for a $2 \times 2$ factorial design (IBM-SPSS Inc., Chicago, IL, USA). The model included the fixed effect of GOD level, CAT level and their interaction. Regarding piglet weight and litter weight at birth, the number of piglets at birth was used as a covariance. Piglet mortality was analyzed by Chi-square. For the sow and litter performance, an individual sow or litter was deemed to the experimental unit. All data were presented as means and standard error of mean. Statistical significance was set at $\mathrm{p} \leq 0.05$ and tendency was declared at $0.05<\mathrm{p}<0.10$. When a significant interaction between GOD and CAT was found, Tukey's multiple range test was used to further analyze the difference among the groups.

\section{RESULTS}

\section{Reproductive performance of sows}

For the performance of sows (Table 4), dietary GOD supplementation increased the average daily feed intake (ADFI) of sows during lactation $(\mathrm{p}<0.05)$, and dietary CAT supplementation shortened the duration of parturition $(\mathrm{p}<0.05)$. For the performance of piglets (Table 5), no significant interaction between GOD and CAT was found. Dietary GOD supplementation significantly elevated litter weight at weaning $(\mathrm{p}<0.05)$. Dietary CAT supplementation enhanced litter weight, $\mathrm{BW}$, and ADG of weaned piglets, and reduced the number of stillbirth and pre-weaning mortality $(\mathrm{p}<0.05)$.

\section{Antioxidant status in plasma of sows}

The effects of dietary GOD and CAT supplementation on antioxidant enzyme activities in plasma of sows were shown in Table 6. Dietary GOD supplementation increased T-SOD and GPx activities at L14 and TAC activity at G108 (p<0.05). Dietary CAT supplementation enhanced CAT activity at G108, L1 and L14, TAC activity at G108 and L1, T-SOD activity at L14, and GPx activity at L1 and L14 in plasma of sows ( $\mathrm{p}<$ 0.05 ). The change of oxidative stress products in plasma was shown in Table 7. Dietary GOD supplementation decreased 
Table 4. Effects of dietary GOD and CAT supplementation on performance of sows

\begin{tabular}{|c|c|c|c|c|c|c|c|c|}
\hline \multirow{2}{*}{ Item } & \multicolumn{2}{|c|}{$0 \mathrm{U} / \mathrm{kg} \mathrm{GOD}$} & \multicolumn{2}{|l|}{$60 \mathrm{U} / \mathrm{kg} \mathrm{GOD}$} & \multirow{2}{*}{ SEM } & \multicolumn{3}{|c|}{ p-value } \\
\hline & $0 \mathrm{U} / \mathrm{kg}$ CAT & $75 \mathrm{U} / \mathrm{kg}$ CAT & O U/ kg CAT & $75 \mathrm{U} / \mathrm{kg}$ CAT & & GOD & CAT & GOD $\times C A T$ \\
\hline$\overline{n^{1)}}$ & 22 & 25 & 23 & 24 & & & & \\
\hline Parity & 4.77 & 4.84 & 4.35 & 4.50 & 0.267 & 0.156 & 0.682 & 0.874 \\
\hline \multicolumn{9}{|l|}{ Backfat of sows (mm) } \\
\hline Breeding & 14.43 & 14.00 & 14.33 & 14.31 & 0.479 & 0.830 & 0.643 & 0.664 \\
\hline Day 108 of gestation & 18.14 & 18.16 & 18.33 & 18.40 & 0.328 & 0.517 & 0.887 & 0.944 \\
\hline Gain & 3.71 & 4.16 & 4.00 & 4.08 & 0.373 & 0.770 & 0.472 & 0.619 \\
\hline Parturition & 18.43 & 18.36 & 18.39 & 18.23 & 0.319 & 0.789 & 0.714 & 0.888 \\
\hline Weaning & 13.52 & 13.02 & 13.39 & 12.71 & 0.405 & 0.586 & 0.147 & 0.824 \\
\hline Loss & 4.91 & 5.34 & 5.00 & 5.52 & 0.301 & 0.653 & 0.117 & 0.882 \\
\hline Lactation feed intake $(\mathrm{kg} / \mathrm{d})$ & 6.58 & 6.43 & 6.67 & 6.91 & 0.111 & 0.013 & 0.711 & 0.090 \\
\hline Farrowing duration ${ }^{2)}$ (min) & 202.50 & 180.40 & 185.65 & 170.71 & 8.341 & 0.115 & 0.029 & 0.669 \\
\hline WEI (d) & 6.67 & 6.24 & 6.00 & 5.80 & 0.396 & 0.167 & 0.429 & 0.773 \\
\hline
\end{tabular}

Data are means \pm standard error of the mean.

GOD, glucose oxidase; CAT, catalase; SEM, standard error of the mean; WEl, the weaning-to-estrus interval

1) The number of sows for analysis.

2) Farrowing duration refers to the time interval between the birth of first piglet and the complete expulsion of placenta.

Statistical significance for main effects and interactions was set at $p \leq 0.05$ and tendency was declared at $0.05<p<0.10$.

Table 5. Effect of dietary GOD and CAT supplementation on performance of piglets

\begin{tabular}{|c|c|c|c|c|c|c|c|c|}
\hline \multirow{2}{*}{ Item } & \multicolumn{2}{|c|}{$0 \mathrm{U} / \mathrm{kg}$ GOD } & \multicolumn{2}{|c|}{$60 \mathrm{U} / \mathrm{kg}$ GOD } & \multirow{2}{*}{ SEM } & \multicolumn{3}{|c|}{ p-value } \\
\hline & $0 \mathrm{U} / \mathrm{kg}$ CAT & 75 U/kg CAT & $0 \mathrm{U} / \mathrm{kg}$ CAT & 75 U/kg CAT & & GOD & CAT & GOD $\times C A T$ \\
\hline$n$ & 22 & 25 & 23 & 24 & & & & \\
\hline Total born & 11.82 & 12.20 & 12.13 & 12.13 & 0.456 & 0.795 & 0.681 & 0.672 \\
\hline Born alive & 10.59 & 11.56 & 11.39 & 11.71 & 0.365 & 0.198 & 0.082 & 0.375 \\
\hline After cross-foster & 10.73 & 10.72 & 10.87 & 10.79 & 0.169 & 0.527 & 0.801 & 0.835 \\
\hline Mummy & 0.36 & 0.20 & 0.26 & 0.13 & 0.124 & 0.473 & 0.228 & 0.911 \\
\hline Weaned piglets & 9.68 & 10.20 & 10.17 & 10.38 & 0.192 & 0.086 & 0.064 & 0.411 \\
\hline \multicolumn{9}{|l|}{ Litter weight (kg) } \\
\hline At birth ${ }^{1)}$ & 16.22 & 16.58 & 16.10 & 16.22 & 0.465 & 0.612 & 0.612 & 0.794 \\
\hline After cross-foster & 16.64 & 16.49 & 16.75 & 16.70 & 0.304 & 0.600 & 0.747 & 0.874 \\
\hline After cross-foster & 1.56 & 1.54 & 1.54 & 1.55 & 0.018 & 0.870 & 0.753 & 0.585 \\
\hline At day 7 & 2.69 & 2.72 & 2.73 & 2.78 & 0.045 & 0.289 & 0.319 & 0.886 \\
\hline At day 21 & 5.66 & 5.86 & 5.82 & 6.04 & 0.105 & 0.108 & 0.047 & 0.889 \\
\hline \multicolumn{9}{|l|}{ Piglet ADG (g/d) } \\
\hline Day 1 to 7 & 161.56 & 169.22 & 169.01 & 175.80 & 5.105 & 0.173 & 0.161 & 0.932 \\
\hline Day 1 to 21 & 195.44 & 205.67 & 203.40 & 214.07 & 4.739 & 0.088 & 0.030 & 0.963 \\
\hline \multicolumn{9}{|l|}{ Piglet mortality ${ }^{2)}(\%)$} \\
\hline At birth & $9.59^{\mathrm{a}}$ & $4.47^{\mathrm{ab}}$ & $5.54^{\mathrm{ab}}$ & $2.78^{b}$ & - & - & - & 0.007 \\
\hline At day 21 & $9.67^{a}$ & $4.83^{b}$ & $6.22^{\mathrm{ab}}$ & $3.70^{b}$ & - & - & - & 0.037 \\
\hline
\end{tabular}

Data are means \pm standard error of the mean.

GOD, glucose oxidase; CAT, catalase; SEM, standard error of the mean; BW, body weight; ADG, average daily gain.

1) Piglet number as a covariate.

2) Piglet mortality was analyzed by Chi-square.

Statistical significance for main effects and interactions was set at $p \leq 0.05$ and tendency was declared at $0.05<p<0.10$.

a,b Means within a row with different superscripts differ $(p \leq 0.05)$. 
Table 6. Effects of dietary GOD and CAT supplementation on antioxidant enzyme activities in plasma of sows

\begin{tabular}{|c|c|c|c|c|c|c|c|c|}
\hline \multirow{2}{*}{ Item } & \multicolumn{2}{|c|}{$0 \mathrm{U} / \mathrm{kg}$ GOD } & \multicolumn{2}{|c|}{$60 \mathrm{U} / \mathrm{kg} \mathrm{GOD}$} & \multirow{2}{*}{ SEM } & \multicolumn{3}{|c|}{ p-value } \\
\hline & $0 \mathrm{U} / \mathrm{kg}$ CAT & 75 U/kg CAT & $0 \mathrm{U} / \mathrm{kg}$ CAT & $75 \mathrm{U} / \mathrm{kg}$ CAT & & GOD & CAT & GOD $\times C A T$ \\
\hline \multicolumn{9}{|c|}{ Day 28 of gestation } \\
\hline $\mathrm{TAC}(\mathrm{U} / \mathrm{mL})$ & 3.18 & 3.38 & 3.23 & 3.60 & 0.180 & 0.461 & 0.135 & 0.640 \\
\hline T-SOD (U/mL) & 126.58 & 132.20 & 128.64 & 133.42 & 4.357 & 0.712 & 0.250 & 0.924 \\
\hline CAT $(\mathrm{U} / \mathrm{mL})$ & 4.51 & 4.44 & 4.10 & 4.74 & 0.223 & 0.809 & 0.223 & 0.132 \\
\hline $\mathrm{GPx}(\mathrm{U} / \mathrm{mL})$ & 221.48 & 224.98 & 223.45 & 226.08 & 3.320 & 0.650 & 0.369 & 0.897 \\
\hline \multicolumn{9}{|c|}{ Day 80 of gestation } \\
\hline TAC (U/mL) & 4.41 & 4.64 & 4.34 & 4.91 & 0.235 & 0.676 & 0.111 & 0.474 \\
\hline T-SOD (U/mL) & 147.22 & 147.32 & 142.88 & 152.20 & 4.394 & 0.952 & 0.300 & 0.310 \\
\hline CAT (U/mL) & 8.32 & 9.04 & 8.46 & 8.78 & 0.320 & 0.854 & 0.126 & 0.545 \\
\hline $\mathrm{GPx}(\mathrm{U} / \mathrm{mL})$ & 198.25 & 197.56 & 205.26 & 202.74 & 3.550 & 0.106 & 0.661 & 0.796 \\
\hline \multicolumn{9}{|c|}{ Day 108 of gestation } \\
\hline $\mathrm{TAC}(\mathrm{U} / \mathrm{mL})$ & 5.08 & 5.60 & 5.38 & 6.31 & 0.206 & 0.026 & 0.003 & 0.320 \\
\hline T-SOD (U/mL) & 138.38 & 144.48 & 140.66 & 147.38 & 4.005 & 0.527 & 0.129 & 0.939 \\
\hline CAT (U/mL) & 7.20 & 8.08 & 7.79 & 8.31 & 0.278 & 0.158 & 0.022 & 0.524 \\
\hline $\mathrm{GPx}(\mathrm{U} / \mathrm{mL})$ & 217.97 & 221.92 & 219.29 & 221.81 & 3.141 & 0.850 & 0.318 & 0.823 \\
\hline \multicolumn{9}{|l|}{ Day 1 of lactation } \\
\hline $\mathrm{TAC}(\mathrm{U} / \mathrm{mL})$ & 5.58 & 6.29 & 5.70 & 6.81 & 0.224 & 0.173 & 0.001 & 0.387 \\
\hline T-SOD (U/mL) & 138.06 & 139.08 & 134.24 & 143.04 & 3.024 & 0.982 & 0.124 & 0.217 \\
\hline CAT (U/mL) & 12.22 & 12.95 & 12.36 & 13.44 & 0.326 & 0.351 & 0.014 & 0.603 \\
\hline $\mathrm{GPx}(\mathrm{U} / \mathrm{mL})$ & 208.90 & 211.54 & 206.00 & 221.34 & 3.556 & 0.346 & 0.022 & 0.093 \\
\hline \multicolumn{9}{|l|}{ Day 14 of lactation } \\
\hline TAC (U/mL) & 4.22 & 4.27 & 4.17 & 4.64 & 0.205 & 0.446 & 0.222 & 0.320 \\
\hline T-SOD (U/mL) & 90.48 & 97.18 & 96.22 & 105.00 & 3.064 & 0.042 & 0.022 & 0.739 \\
\hline CAT $(\mathrm{U} / \mathrm{mL})$ & 5.23 & 5.52 & 5.09 & 6.31 & 0.283 & 0.265 & 0.017 & 0.121 \\
\hline $\mathrm{GPx}(\mathrm{U} / \mathrm{mL})$ & 187.12 & 194.68 & 190.22 & 209.12 & 4.112 & 0.049 & 0.005 & 0.187 \\
\hline
\end{tabular}

Data are means \pm standard error of the mean $(n=6)$.

GOD, glucose oxidase; CAT, catalase; SEM, standard error of the mean; TAC, total antioxidant capacity; T-SOD, total superoxide dismutase; GPx, glutathione peroxidase.

Statistical significance for main effects and interactions was set at $p \leq 0.05$ and tendency was declared at $0.05<p<0.10$.

MDA level at L1 and L14 and 8-OHdG level at G108 and L1 $(\mathrm{p}<0.05)$. Meanwhile, dietary CAT supplementation reduced MDA and 8-OHdG levels at G108, L1, and L14 and ROS level at L1 $(\mathrm{p}<0.05)$. Interestingly, the levels of MDA and ROS revealed interactions between GOD and CAT at L1 and L14 $(\mathrm{p}<0.05)$. The addition of CAT reduced MDA level at $\mathrm{L} 1$ and L14 in the basal diet and reduced ROS level at L1 in the GOD diet. The TBARS level was not affected by dietary GOD and CAT supplementation.

\section{Antioxidant status in plasma of piglets}

As shown in Table 8, dietary GOD supplementation significantly enhanced TAC and T-SOD activities and simultaneously reduced MDA level in plasma of weaned piglets $(\mathrm{p}<0.05)$. Dietary CAT supplementation enhanced TAC, T-SOD, CAT, and GPx activities and lessened MDA level in plasma of weaned piglets $(\mathrm{p}<0.05)$. Besides, dietary CAT supplementation elevated CAT activity in plasma of newborn piglets $(\mathrm{p}<0.05)$.

Antioxidant status in colostrum and milk

The effects of dietary GOD and CAT supplementation on antioxidant capacity in milk were shown in Table 9. Dietary GOD supplementation significantly enhanced T-SOD and GPx activities in 14-d milk $(\mathrm{p}<0.05)$. Dietary CAT supplementation enhanced TAC, CAT, and GPx activities $(\mathrm{p}<0.05)$ and decreased MDA level $(\mathrm{p}<0.05)$ in 14 -d milk. However, the antioxidant capacity of colostrum was unaffected by dietary GOD and CAT supplementation.

\section{Fecal microflora}

Fecal Microflora of sows was shown in Table 10. There was a significant interaction between GOD and CAT on fecal Escherichia coli (E. coli) counts at G28, G108, and L14 (p<0.05). The GOD diet significantly reduced fecal $E$. coli counts ( $\mathrm{p}<$ 0.05), but the addition of CAT did not inhibit $E$. coli counts in the GOD diet. Dietary GOD supplementation markedly reduced fecal E. coli counts and increased fecal Lactobacillus counts at G28, G108, and L14 ( $\mathrm{p}<0.05)$.

\section{Apoptosis detected by transferase-mediated dUTP nick-end labeling assay}

The apoptosis rate of the liver, endometrium, and ovarian granulosa cells in sows was detected by TUNEL in situ label- 
Table 7. Effects of dietary GOD and CAT supplementation on oxidative stress products in plasma of sows

\begin{tabular}{|c|c|c|c|c|c|c|c|c|}
\hline \multirow{2}{*}{ Item } & \multicolumn{2}{|c|}{$0 \mathrm{U} / \mathrm{kg}$ GOD } & \multicolumn{2}{|c|}{$60 \mathrm{U} / \mathrm{kg}$ GOD } & \multirow{2}{*}{ SEM } & \multicolumn{3}{|c|}{ p-value } \\
\hline & $0 \mathrm{U} / \mathrm{kg}$ CAT & 75 U/kg CAT & $0 \mathrm{U} / \mathrm{kg}$ CAT & 75 U/kg CAT & & GOD & CAT & GOD $\times C A T$ \\
\hline \multicolumn{9}{|l|}{ Day 28 of gestation } \\
\hline ROS (U/mL) & 182.45 & 168.54 & 178.84 & 171.20 & 6.636 & 0.944 & 0.124 & 0.643 \\
\hline TBARS (nmol/mL) & 65.77 & 60.85 & 63.25 & 62.36 & 2.080 & 0.810 & 0.181 & 0.347 \\
\hline 8-OHdG (ng/mL) & 19.01 & 17.73 & 18.05 & 18.13 & 0.554 & 0.615 & 0.292 & 0.235 \\
\hline MDA (nmol/mL) & 4.87 & 4.57 & 4.68 & 4.22 & 0.223 & 0.253 & 0.109 & 0.731 \\
\hline ROS (U/mL) & 211.30 & 199.97 & 214.79 & 205.20 & 6.132 & 0.487 & 0.107 & 0.889 \\
\hline TBARS (nmol/mL) & 81.25 & 78.62 & 79.69 & 75.86 & 2.253 & 0.352 & 0.171 & 0.794 \\
\hline 8-OHdG (ng/mL) & 28.26 & 27.22 & 27.33 & 26.52 & 0.566 & 0.170 & 0.122 & 0.836 \\
\hline \multicolumn{9}{|l|}{ Day 108 of gestation } \\
\hline MDA (nmol/mL) & 5.09 & 4.60 & 4.98 & 4.38 & 0.236 & 0.479 & 0.034 & 0.812 \\
\hline MDA (nmol/mL) & $5.45^{\mathrm{a}}$ & $4.37^{\mathrm{b}}$ & $4.46^{b}$ & $4.28^{b}$ & 0.200 & 0.016 & 0.006 & 0.040 \\
\hline ROS (U/mL) & $353.87^{\mathrm{a}}$ & $341.00^{\mathrm{ab}}$ & $367.90^{\mathrm{a}}$ & $317.48^{b}$ & 8.806 & 0.597 & 0.002 & 0.049 \\
\hline TBARS (nmol/mL) & 164.22 & 156.22 & 159.84 & 154.76 & 4.040 & 0.481 & 0.125 & 0.722 \\
\hline 8-OHdG (ng/mL) & 42.94 & 40.21 & 41.38 & 39.19 & 0.550 & 0.032 & $<0.001$ & 0.633 \\
\hline \multicolumn{9}{|l|}{ Day 14 of lactation } \\
\hline MDA (nmol/mL) & $4.43^{\mathrm{a}}$ & $3.44^{b}$ & $3.60^{b}$ & $3.29^{b}$ & 0.156 & 0.006 & 0.001 & 0.046 \\
\hline ROS (U/mL) & 226.25 & 222.91 & 230.60 & 213.79 & 6.235 & 0.707 & 0.126 & 0.296 \\
\hline TBARS (nmol/mL) & 73.16 & 71.74 & 71.69 & 68.96 & 2.865 & 0.469 & 0.479 & 0.823 \\
\hline 8-OHdG (ng/mL) & 33.58 & 32.18 & 32.57 & 31.64 & 0.509 & 0.149 & 0.036 & 0.648 \\
\hline
\end{tabular}

Data are means \pm standard error of the mean $(n=6)$.

GOD, glucose oxidase; CAT, catalase; SEM, standard error of the mean; MDA, malondialdehyde; ROS, reactive oxygen species; TBARS, thiobarbituric acid reactive substances; 8-OHdG, 8-hydroxy-deoxyguanosine.

Statistical significance for main effects and interactions was set at $p \leq 0.05$ and tendency was declared at $0.05<p<0.10$.

$a, b$ Means within a row with different superscripts differ $(p \leq 0.05)$.

ing at weaning (Table 11). Dietary GOD supplementation significantly reduced the apoptotic rate of the liver and ovarian granulosa cells $(\mathrm{p}<0.05)$. Accordingly, dietary CAT supplemen- tation reduced the apoptosis rate of the liver, endometrium, and ovarian granulosa cells at day 21 of lactation $(\mathrm{p}<0.05)$.

Table 8. Effects of dietary GOD and CAT supplementation on antioxidant status in plasma of piglets

\begin{tabular}{|c|c|c|c|c|c|c|c|c|}
\hline \multirow{2}{*}{ Item } & \multicolumn{2}{|c|}{$0 \mathrm{U} / \mathrm{kg}$ GOD } & \multicolumn{2}{|c|}{$60 \mathrm{U} / \mathrm{kg}$ GOD } & \multirow{2}{*}{ SEM } & \multicolumn{3}{|c|}{ p-value } \\
\hline & $0 \mathrm{U} / \mathrm{kg}$ CAT & 75 U/kg CAT & $0 \mathrm{U} / \mathrm{kg}$ CAT & $75 \mathrm{U} / \mathrm{kg}$ CAT & & GOD & CAT & GOD $\times C A T$ \\
\hline \multicolumn{9}{|l|}{ At birth } \\
\hline T-SOD (U/mL) & 117.56 & 120.04 & 122.22 & 124.40 & 2.826 & 0.130 & 0.422 & 0.958 \\
\hline CAT $(\mathrm{U} / \mathrm{mL})$ & 2.87 & 3.12 & 2.94 & 3.32 & 0.145 & 0.364 & 0.042 & 0.679 \\
\hline $\mathrm{GPx}(\mathrm{U} / \mathrm{mL})$ & 144.90 & 151.10 & 149.10 & 157.54 & 4.41 & 0.342 & 0.171 & 0.637 \\
\hline $\mathrm{TAC}(\mathrm{U} / \mathrm{mL})$ & 8.24 & 8.73 & 8.76 & 9.40 & 0.261 & 0.038 & 0.046 & 0.786 \\
\hline T-SOD (U/mL) & 131.54 & 139.42 & 141.26 & 146.68 & 3.041 & 0.013 & 0.044 & 0.691 \\
\hline CAT (U/mL) & 3.12 & 3.59 & 3.35 & 3.75 & 0.189 & 0.309 & 0.035 & 0.864 \\
\hline $\mathrm{GPx}(\mathrm{U} / \mathrm{mL})$ & 162.00 & 170.90 & 167.76 & 179.54 & 4.795 & 0.153 & 0.047 & 0.768 \\
\hline $\operatorname{MDA}(\mathrm{nmol} / \mathrm{mL})$ & 3.48 & 2.77 & 2.71 & 2.52 & 0.204 & 0.024 & 0.044 & 0.218 \\
\hline
\end{tabular}

Data are means \pm standard error of the mean $(n=6)$.

GOD, glucose oxidase; CAT, catalase; SEM, standard error of the mean; TAC, total antioxidant capacity; T-SOD, total superoxide dismutase; GPx, glutathione peroxidase; MDA, malondialdehyde.

Statistical significance for main effects and interactions was set at $p \leq 0.05$ and tendency was declared at $0.05<p<0.10$. 
Table 9. Effects of dietary GOD and CAT supplementation on the antioxidant status of milk

\begin{tabular}{|c|c|c|c|c|c|c|c|c|}
\hline \multirow{2}{*}{ Item } & \multicolumn{2}{|c|}{$0 \mathrm{U} / \mathrm{kg}$ GOD } & \multicolumn{2}{|c|}{$60 \mathrm{U} / \mathrm{kg}$ GOD } & \multirow{2}{*}{ SEM } & \multicolumn{3}{|c|}{ p-value } \\
\hline & $0 \mathrm{U} / \mathrm{kg}$ CAT & 75 U/kg CAT & $0 \mathrm{U} / \mathrm{kg}$ CAT & 75 U/kg CAT & & GOD & CAT & GOD $\times C A T$ \\
\hline \multicolumn{9}{|l|}{ Colostrum } \\
\hline T-SOD (U/mL) & 265.52 & 270.52 & 269.84 & 277.90 & 3.791 & 0.142 & 0.104 & 0.692 \\
\hline CAT (U/mL) & 7.66 & 8.24 & 8.07 & 8.37 & 0.263 & 0.315 & 0.113 & 0.589 \\
\hline $\mathrm{GPx}(\mathrm{U} / \mathrm{mL})$ & 120.90 & 124.24 & 126.88 & 130.42 & 4.134 & 0.161 & 0.418 & 0.981 \\
\hline TAC (U/mL) & 21.95 & 24.94 & 23.36 & 24.54 & 0.699 & 0.481 & 0.009 & 0.216 \\
\hline T-SOD (U/mL) & 221.42 & 229.96 & 232.86 & 238.20 & 3.485 & 0.012 & 0.064 & 0.652 \\
\hline CAT (U/mL) & 4.99 & 5.65 & 5.38 & 6.08 & 0.205 & 0.059 & 0.004 & 0.912 \\
\hline $\mathrm{GPx}(\mathrm{U} / \mathrm{mL})$ & 90.22 & 99.10 & 98.42 & 102.22 & 2.579 & 0.043 & 0.026 & 0.339 \\
\hline $\mathrm{MDA}(\mathrm{nmol} / \mathrm{mL})$ & 5.79 & 5.26 & 5.54 & 4.83 & 0.217 & 0.135 & 0.012 & 0.674 \\
\hline
\end{tabular}

Data are means \pm standard error of the mean $(n=6)$.

GOD, glucose oxidase; CAT, catalase; SEM, standard error of the mean; TAC, total antioxidant capacity; T-SOD, total superoxide dismutase; GPx, glutathione peroxidase; MDA, malondialdehyde.

Statistical significance for main effects and interactions was set at $p \leq 0.05$ and tendency was declared at $0.05<p<0.10$.

Table 10. Effects of dietary GOD and CAT supplementation on fecal bacterial counts in sows

\begin{tabular}{|c|c|c|c|c|c|c|c|c|}
\hline \multirow{2}{*}{ Item } & \multicolumn{2}{|c|}{$0 \mathrm{U} / \mathrm{kg}$ GOD } & \multicolumn{2}{|c|}{$60 \mathrm{U} / \mathrm{kg} \mathrm{GOD}$} & \multirow{2}{*}{ SEM } & \multicolumn{3}{|c|}{ p-value } \\
\hline & $0 \mathrm{U} / \mathrm{kg}$ CAT & 75 U/kg CAT & $0 \mathrm{U} / \mathrm{kg}$ CAT & 75 U/kg CAT & & GOD & CAT & GOD $\times C A T$ \\
\hline \multicolumn{9}{|c|}{ Bifidobacterium $\left(\log _{10} \mathrm{cfu} / \mathrm{g}\right)$} \\
\hline G108 & 9.13 & 9.42 & 9.59 & 9.54 & 0.162 & 0.091 & 0.466 & 0.312 \\
\hline L14 & 8.75 & 8.84 & 9.11 & 9.20 & 0.192 & 0.079 & 0.639 & 0.992 \\
\hline \multicolumn{9}{|c|}{ Lactobacillus ( $\log _{10} \mathrm{cfu} / \mathrm{g}$ ) } \\
\hline L14 & 10.72 & 11.08 & 11.52 & 11.71 & 0.165 & 0.001 & 0.111 & 0.623 \\
\hline \multicolumn{9}{|c|}{ Escherichia coli $\left(\log _{10} \mathrm{cfu} / \mathrm{g}\right)$} \\
\hline $\mathrm{G} 28$ & $12.31^{\mathrm{a}}$ & $12.01^{\mathrm{ab}}$ & $11.51^{b}$ & $11.90^{\mathrm{ab}}$ & 0.137 & 0.004 & 0.791 & 0.023 \\
\hline G108 & $12.09^{\mathrm{a}}$ & $11.82^{\mathrm{a}}$ & $11.34^{b}$ & $11.62^{\mathrm{ab}}$ & 0.115 & 0.001 & 0.973 & 0.030 \\
\hline L14 & $12.48^{\mathrm{a}}$ & $12.08^{\mathrm{ab}}$ & $11.62^{b}$ & $11.97^{\mathrm{ab}}$ & 0.136 & 0.002 & 0.856 & 0.014 \\
\hline
\end{tabular}

Data are means \pm standard error of the mean $(n=6)$.

GOD, glucose oxidase; CAT, catalase; SEM, standard error of the mean; cfu, colony-forming unit.

Statistical significance for main effects and interactions was set at $p \leq 0.05$ and tendency was declared at $0.05<p<0.10$.

${ }_{a, b}$ Means within a row with different superscripts differ $(p \leq 0.05)$.

mRNA expression of apoptosis-related genes

In the liver (Table 12), dietary GOD supplementation markedly decreased caspase- 3 and caspase- 9 gene expression $(\mathrm{p}<0.05)$, while dietary CAT supplementation significantly reduced $\mathrm{Bax} / \mathrm{Bcl}-2$ ratio, caspase-3, and caspase-9 gene expression $(\mathrm{p}<0.05)$. In the ovary and uterus, dietary GOD

Table 11. Effect of dietary GOD and CAT supplementation on the apoptosis rate of the liver, endometrium, and ovarian granulosa cells in sows at weaning

\begin{tabular}{|c|c|c|c|c|c|c|c|c|}
\hline \multirow{2}{*}{ Item } & \multicolumn{2}{|c|}{$0 \mathrm{U} / \mathrm{kg}$ GOD } & \multicolumn{2}{|c|}{$60 \mathrm{U} / \mathrm{kg} \mathrm{GOD}$} & \multirow{2}{*}{ SEM } & \multicolumn{3}{|c|}{ p-value } \\
\hline & $0 \mathrm{U} / \mathrm{kg}$ CAT & $75 \mathrm{U} / \mathrm{kg}$ CAT & $0 \mathrm{U} / \mathrm{kg}$ CAT & 75 U/kg CAT & & GOD & CAT & GOD $\times C A T$ \\
\hline Liver (\%) & 12.06 & 9.70 & 10.02 & 8.65 & 0.720 & 0.048 & 0.020 & 0.501 \\
\hline Ovarian granulosa cells (\%) & 15.36 & 10.89 & 12.26 & 9.80 & 0.950 & 0.043 & 0.002 & 0.307 \\
\hline
\end{tabular}

Data are means \pm standard error of the mean $(n=5)$.

GOD, glucose oxidase; CAT, catalase; SEM, standard error of the mean.

Statistical significance for main effects and interactions was set at $p \leq 0.05$ and tendency was declared at $0.05<p<0.10$. 
Table 12. Effects of dietary GOD and CAT supplementation on apoptosis-related gene expression of the liver, ovary, and uterus in sows at weaning

\begin{tabular}{|c|c|c|c|c|c|c|c|c|}
\hline \multirow{2}{*}{ Item } & \multicolumn{2}{|c|}{$0 \mathrm{U} / \mathrm{kg}$ GOD } & \multicolumn{2}{|c|}{$60 \mathrm{U} / \mathrm{kg} \mathrm{GOD}$} & \multirow{2}{*}{ SEM } & \multicolumn{3}{|c|}{$p$-value } \\
\hline & $0 \mathrm{U} / \mathrm{kg}$ CAT & $75 \mathrm{U} / \mathrm{kg}$ CAT & $0 \mathrm{U} / \mathrm{kg}$ CAT & $75 \mathrm{U} / \mathrm{kg}$ CAT & & GOD & CAT & GOD $\times C A T$ \\
\hline \multicolumn{9}{|l|}{ Liver } \\
\hline Fas & 1.000 & 0.936 & 0.955 & 0.909 & 0.033 & 0.278 & 0.108 & 0.783 \\
\hline Bax & 1.000 & 0.890 & 0.922 & 0.918 & 0.040 & 0.518 & 0.163 & 0.194 \\
\hline Bcl-2 & 1.000 & 1.133 & 1.094 & 1.147 & 0.045 & 0.255 & 0.057 & 0.402 \\
\hline Bax/Bcl-2 ratio & 1.000 & 0.791 & 0.849 & 0.812 & 0.053 & 0.232 & 0.033 & 0.120 \\
\hline Caspase-3 & 1.000 & 0.861 & 0.891 & 0.832 & 0.027 & 0.020 & 0.002 & 0.147 \\
\hline Caspase-8 & 1.000 & 0.895 & 0.920 & 0.907 & 0.052 & 0.515 & 0.268 & 0.389 \\
\hline Caspase-9 & 1.000 & 0.872 & 0.884 & 0.816 & 0.040 & 0.048 & 0.028 & 0.470 \\
\hline \multicolumn{9}{|l|}{ Ovary } \\
\hline Fas & 1.000 & 0.943 & 0.961 & 0.965 & 0.032 & 0.783 & 0.410 & 0.340 \\
\hline Bax & 1.000 & 0.940 & 0.954 & 0.886 & 0.045 & 0.277 & 0.170 & 0.943 \\
\hline Bcl-2 & 1.000 & 1.124 & 1.125 & 1.106 & 0.044 & 0.250 & 0.262 & 0.128 \\
\hline Bax/Bcl-2 ratio & 1.000 & 0.836 & 0.846 & 0.813 & 0.038 & 0.034 & 0.021 & 0.104 \\
\hline Caspase-3 & 1.000 & 0.906 & 0.903 & 0.837 & 0.035 & 0.030 & 0.037 & 0.684 \\
\hline Caspase-8 & 1.000 & 1.008 & 0.981 & 0.955 & 0.035 & 0.310 & 0.792 & 0.663 \\
\hline Caspase-9 & 1.000 & 0.840 & 0.863 & 0.804 & 0.031 & 0.012 & 0.002 & 0.114 \\
\hline \multicolumn{9}{|l|}{ Uterus } \\
\hline Fas & 1.000 & 0.926 & 0.948 & 0.958 & 0.038 & 0.777 & 0.400 & 0.277 \\
\hline Bax & 1.000 & 0.939 & 0.947 & 0.903 & 0.037 & 0.235 & 0.167 & 0.803 \\
\hline Bcl-2 & 1.000 & 1.222 & 1.147 & 1.205 & 0.059 & 0.293 & 0.032 & 0.188 \\
\hline Bax/Bcl-2 ratio & 1.000 & 0.779 & 0.828 & 0.754 & 0.038 & 0.018 & 0.001 & 0.067 \\
\hline Caspase-3 & 1.000 & 0.883 & 0.910 & 0.849 & 0.029 & 0.047 & 0.007 & 0.343 \\
\hline Caspase-8 & 1.000 & 0.934 & 0.992 & 0.977 & 0.033 & 0.616 & 0.233 & 0.442 \\
\hline Caspase-9 & 1.000 & 0.867 & 0.882 & 0.804 & 0.037 & 0.025 & 0.011 & 0.450 \\
\hline
\end{tabular}

Data are means \pm standard error of the mean $(n=5)$.

GOD, glucose oxidase; CAT, catalase; SEM, standard error of the mean.

Statistical significance for main effects and interactions was set at $p \leq 0.05$ and tendency was declared at $0.05<p<0.10$.

and CAT supplementation lessened Bax/Bcl-2 ratio, caspase-3, and caspase-9 gene expression $(\mathrm{p}<0.05)$.

\section{DISCUSSION}

The study hypothesized that dietary GOD and CAT supplementation could enhance reproductive performance and alleviate oxidative stress and apoptosis in sows. Tang et al [5] reported that dietary GOD (100 U/kg diet) supplementation in piglets had a greater ADG and lower feed conversion ratio. In this study, dietary GOD supplementation elevated feed intake of sows during lactation. This could be connected with gluconic acid, which was produced by GOD catalyzing glucose. In the obesity model, the most direct factors involved in insulin resistance are the increase of pro-inflammatory factors and FFA [19]. Gluconic acid produces volatile shortchain fatty acids (SCFA) through fermentation in the large intestine [7]. The increase of SCFA, especially acetic acid, is beneficial to decrease FFA concentration in the blood, which has been proved to improve insulin sensitivity [19]. It was also reported that improving insulin sensitivity during late pregnancy and early lactation could increase feed intake of sows during lactation [20]. Therefore, dietary GOD supple- mentation could elevate feed intake of sows during lactation, which may be related to the decrease of insulin resistance. In this study, dietary GOD supplementation improved litter weight at weaning, which could be associated with higher ADFI of sows. Sows having higher feed intake could produce enough milk to sustain the normal growth of piglets [21]. It is easy for sows to generate more weak and stillborn piglets if the duration of parturition is too long [22]. This study showed that dietary CAT supplementation decreased the duration of labor and stillbirth in sows. This is consistent with the previous study reporting that the stillborn rate of sows with a long duration of farrowing $(>3 \mathrm{~h})$ was twice that of sows with a short duration of farrowing $(<3 \mathrm{~h})$ [22]. Additionally, dietary CAT supplementation had lower weaned piglet mortality, which could be due to the lower oxidative stress level of sows. High intensity of the oxidative stress during lactation made sows upset, causing sows to move frequently after farrowing, and hence crushed one-week-old piglets [23]. Dietary CAT supplementation enhanced litter weight, BW, and ADG of piglets at weaning, suggesting that the growth performance of piglets from birth to weaning could be improved by milk. The quality of milk is affected by the health status of sows [23]. However, no significant interaction be- 
tween GOD and CAT was observed on the reproductive performance of sows in this study.

With the rapid growth of fetus and milk yield, the demand for energy and oxygen levels of sows also continues to increase, which produces abundant ROS [3], resulting in DNA damage in sows and piglets [16]. Wang et al [24] observed that oxidative stress was markedly relevant to the reproductive performance of sows. Our study indicated that the antioxidant capacity of sows was improved by dietary GOD supplementation, which was demonstrated by the increase of TAC, TSOD, and GPx activities and the decrease of MDA and 8-OHdG levels in plasma during late gestation and lactation (G108 and L14), alleviating the oxidative stress of sows. In this study, dietary CAT supplementation improved the antioxidant enzyme (TAC, T-SOD, CAT, and GPx) activities and decreased 8-OHdG and MDA concentrations in plasma of sows during late pregnancy and lactation (G108, L1, and L14). This is in accordance with the report showing that the addition of CAT elevated T-SOD and CAT activities and lessened MDA level in plasma of piglets [13]. Additionally, the interactions between GOD and CAT on plasma levels of MDA and ROS in sows during lactation showed that the ability of GOD to reduce the levels of the oxidative stress products was affected by dietary CAT level, and GOD combined with CAT could better alleviate the oxidative damage of lactating sows.

After farrowing, primiparous, old sows and their progeny may undergo severe oxidative stress [4]. The milk yield and reproductive performance of sows are reduced by the increase of oxidative stress level [18], which directly affects the health status of piglets. Nevertheless, antioxidants in milk can help piglets reduce oxidative stress and improve health status [25]. In the present study, dietary GOD supplementation enhanced the antioxidant enzyme (T-SOD and GPx) activities in 14-d milk. Meanwhile, dietary CAT supplementation improved the antioxidant enzyme (TAC, CAT, and GPx) activities and decreased MDA concentration in 14-d milk. These results indicate that dietary GOD and CAT supplementation partially elevates the antioxidant capacity of 14-d milk. This may be because the antioxidant status of milk is closely related to the levels of oxidative stress products in plasma of sows [23], and GOD and CAT improve the health status of sows, thus affecting the antioxidant capacity of milk. However, dietary GOD and CAT supplementation did not affect the antioxidant enzyme activities of colostrum, possibly because the improvement of antioxidant capacity of sows by GOD and CAT was not enough to influence antioxidant enzyme activities of colostrum. In this study, dietary GOD supplementation improved TAC and T-SOD activities and reduced MDA level in plasma of weaned piglets. Similarly, dietary CAT supplementation elevated antioxidant enzyme (TAC, T-SOD, CAT, and GPx) activities and reduced MDA level in plasma of weaned piglets. Additionally, milk was the only source of antioxidants and nutrients for piglets, because piglets were not fed creep feed or milk replacer during the trial period. These results show that dietary GOD and CAT supplementation can enhance the antioxidant status of milk. Limited studies reported the effects of dietary GOD and CAT supplementation on the antioxidant status of milk and suckling piglets, but some reports had indicated that the addition of antioxidants (i.e., selenium, vitamin E, and resveratrol) reduced the oxidative stress of piglets by improving the antioxidant capacity of sows and milk $[17,26]$. Our results were consistent with these reports and revealed that dietary GOD and CAT supplementation could improve the oxidative status of suckling piglets and milk by elevating the antioxidant capacity of lactating sows. Nevertheless, no interaction between GOD and CAT was found in any parameters of colostrum, milk, and piglets.

Reducing oxidative stress could benefit to improve the reproductive performance and gut health of sows. Wang et al [24] reported that gut microflora was different between the high and low reproductive performance of sows. In this study, we observed that dietary GOD supplementation during gestation and lactation reduced fecal $E$. coli counts, but increased fecal Lactobacillus counts. The reason may be that GOD regulates the host microflora by producing gluconic acid and $\mathrm{H}_{2} \mathrm{O}_{2}$ [5]. Biagi et al [7] observed that gluconic acid as a prebiotic effectively affected the variety of gut microflora. Shortchain fatty acids produced by gluconic acid fermentation, especially butyric acid, has antibacterial property, which inhibits the proliferation of $E$. coli and promotes the propagation of Lactobacillus and Bifidobacterium [27]. Moreover, $\mathrm{H}_{2} \mathrm{O}_{2}$ produced by GOD effectively inhibits and kills harmful microbe in the liquid whole egg [8]. Therefore, the results showed that dietary GOD supplementation had altered the gut microflora, which is beneficial to decrease ROS production, alleviating oxidative stress, and ultimately improved health status in sows. Nevertheless, during gestation and lactation, the counts of fecal Bifidobacterium, Lactobacillus, and E. coli were unaffected by dietary CAT supplementation, contradicting the result that dietary CAT enhanced the relative abundance of Dialister and Bifidobacterium in weaned piglets [14]. The contradiction may be due to the difference in the growth stage (sows versus weaned piglets). The interactions between GOD and CAT indicated that the inhibitory effect of GOD on E. coli varied with dietary CAT level throughout gestation and lactation, and the addition of CAT could weaken the inhibitory effect of GOD on E. coli. Although GOD produces $\mathrm{H}_{2} \mathrm{O}_{2}$, CAT can decompose $\mathrm{H}_{2} \mathrm{O}_{2}$ into $\mathrm{H}_{2} \mathrm{O}$ and $\mathrm{O}_{2}$, thus reducing the antimicrobial effect of $\mathrm{H}_{2} \mathrm{O}_{2}$ produced by GOD. These results are similar to the previous finding in the liquid whole egg [8].

Apoptosis is a genetically controlled and autonomously 
ordered cell death, which is different from necrotic cell death. Apoptosis plays a major role in maintaining normal metabolism and avoids inflammatory responses caused by cell death [28]. At present, it is believed that oxidative stress is closely related to cell apoptosis. Free radicals produced by metabolism or exogenous factors can directly induce apoptosis, which may be a ubiquitous mediator in the process of apoptosis [29]. Through TUNEL analysis, we found that dietary GOD supplementation reduced the apoptosis rate of liver and ovarian granulosa cells, while dietary CAT supplementation significantly decreased the apoptosis rate of the liver, endometrium, and ovarian granulosa cells. These results suggest that exogenous GOD and CAT can reduce the apoptosis of sows, and have certain protective effects on the liver, uterus and ovary during lactation.

A previous study reported that cell apoptosis involved the death receptor pathway and the mitochondrial pathway [30], which was primarily regulated by the caspase family, Bcl-2 family, and MAPK family. The caspase family is the promoter and executor of mammalian cell apoptosis [31]. Caspase-8 activates the death receptor pathway, while caspase- 9 activates the mitochondrial pathway [30]. Activation of caspase- 8 and caspase- 9 further activates downstream caspase- 3 , which acts on specific apoptotic substrates and causes apoptosis [32]. In this study, dietary GOD and CAT supplementation downregulated caspase- 3 and caspase- 9 gene expression in the liver, uterus and ovary of sows at weaning. This indicates that exogenous GOD and CAT suppress the apoptosis of the liver, uterus, and ovary by inhibiting caspase- 9 activation, thus weakening caspase- 3 activation. Additionally, previous studies had shown that the expression level of Bcl-2 and Bax directly influenced the regulation of apoptosis, and the $\mathrm{Bcl}-2 / \mathrm{Bax}$ ratio determined whether cells activated the inhibitory apoptosis mechanism or the accelerative apoptosis mechanism after stimulation [33,34]. In the study, although the gene expression of $\mathrm{Bcl}-2$ and Bax related to mitochondrial apoptosis pathway in the liver and ovary of sows was not inhibited by dietary GOD and CAT supplementation, Bcl-2/Bax ratios in the liver, endometrium, and ovary were significantly decreased, inhibiting the occurrence of apoptosis, which further demonstrated that dietary GOD and CAT supplementation had a positive role in alleviating oxidative damage of lactating sows. However, no interaction between GOD and CAT was observed on cell apoptosis in the liver, ovary, and uterus.

In conclusion, dietary GOD and CAT supplementation elevated the reproductive performance of sows and improved the antioxidant status of sows and piglets. Dietary GOD supplementation regulated fecal microflora of sows, but CAT could reduce the inhibitory effect of GOD on E. coli. Dietary GOD and CAT supplementation alleviated the apoptosis of liver, ovary, and uterus by weakening caspase- 3 and caspase- 9 gene expression.

\section{CONFLICT OF INTEREST}

We certify that there is no conflict of interest with any financial organization regarding the material discussed in the manuscript. Sun X, Piao L, Jin H are employees of CJ Cheiljedang feed (China) R\&D center.

\section{FUNDING}

The authors received no financial support for this article.

\section{ACKNOWLEDGMENTS}

The authors thank the CJ (Shenyang) Feed Co., Ltd. for animal management and technical assistance. This study was made through the grant from Engineering Research Center of North-East Cold Region Beef Cattle Science \& Technology Innovation, Ministry of Education, Yanbian University, China and Chungbuk National University (2019-2020 international project), Korea.

\section{REFERENCES}

1. Kim SW, Weaver AC, Shen YB, Zhao Y. Improving efficiency of sow productivity: nutrition and health. J Anim Sci Biotechnol 2013;4:26. https://doi.org/10.1186/2049-1891-4-26

2. Burton GJ, Jauniaux E, Charnock-Jones DS. The influence of the intrauterine environment on human placental development. Int J Dev Biol 2010;54:303-11. https://doi.org/10.1387/ ijdb.082764gb

3. Berchieri-Ronchi CB, Kim SW, Zhao Y, et al. Oxidative stress status of highly prolific sows during gestation and lactation. Animal 2011;5:1774-9. https://doi.org/10.1017/S175173111 1000772

4. Lipko-Przybylska J, Kankofer M. Antioxidant defence of colostrum and milk in consecutive lactations in sows. Irish Vet J 2012;65:4. https://doi.org/10.1186/2046-0481-65-4

5. Tang H, Yao B, Gao X, et al. Effects of glucose oxidase on the growth performance, serum parameters and faecal microflora of piglets. S Afr J Anim Sci 2016;46:14-20. https://doi.org/10. 4314/sajas.v46i1.2

6. Liu J, Liu G, Chen Z, et al. Effects of glucose oxidase on growth performance, immune function, and intestinal barrier of ducks infected with Escherichia coli O88. Poult Sci 2020;99:6549-58. https://doi.org/10.1016/j.psj.2020.09.038

7. Biagi G, Piva A, Moschini M, Vezzali E, Roth FX. Effect of gluconic acid on piglet growth performance, intestinal microflora, and intestinal wall morphology. J Anim Sci 2006;84: 370-8. https://doi.org/10.2527/2006.842370x

8. Dobbenie D, Uyttendaele M, Debevere J. Antibacterial activity of the glucose-oxidase glucose system in liquid whole egg. J Food Prot 1995;58:273-9. https://doi.org/10.4315/0362-028X- 


\subsubsection{3}

9. Wu S, Li T, Niu H, et al. Effects of glucose oxidase on growth performance, gut function, and cecal microbiota of broiler chickens. Poult Sci 2019;98:828-41. https://doi.org/10.3382/ ps/pey393

10. Fiedurek J, Gromada A. Production of catalase and glucose oxidase by Aspergillus niger using unconventional oxygenation of culture. J Appl Microbiol 2000;89:85-9. https://doi.org/ 10.1046/j.1365-2672.2000.01085.x

11. Jackson RM, Russell WJ, Veal CF. Endogenous and exogenous catalase in reoxygenation lung injury. J Appl Physiol 1992; 72:858-64. https://doi.org/10.1152/jappl.1992.72.3.858

12. Amini MR, Kohram H, Shahaneh AA, et al. The effects of different levels of catalase and superoxide dismutase in modified Beltsville extender on rooster post-thawed sperm quality. Cryobiology 2015;70:226-32. https://doi.org/10.1016/j.cryobiol. 2015.03.001

13. Li Y, Zhao X, Jiang X, et al. Effects of dietary supplementation with exogenous catalase on growth performance, oxidative stress and hepatic apoptosis in weaned piglets challenged with lipopolysaccharide. J Anim Sci 2020;98:skaa067. https:// doi.org/10.1093/jas/skaa067

14. Li Y, Zhao X, Zhang L, et al. Effects of a diet supplemented with exogenous catalase from penicillium notatum on intestinal development and microbiota in weaned piglets. Microorganisms 2020;8:391. https://doi.org/10.3390/micro organisms 8030391

15. Bao J, Furumoto K, Yoshimoto M, Fukunaga K, Nakao K. Competitive inhibition by hydrogen peroxide produced in glucose oxidation catalyzed by glucose oxidase. Biochem Eng J 2003;13:69-72. https://doi.org/10.1016/S1369-703X(02) 00120-1

16. Tan C, Wei H, Sun H, et al. Effects of dietary supplementation of oregano essential oil to sows on oxidative stress status, lactation feed intake of sows, and piglet performance. Biomed Res Int 2015;2015:Article ID 525218. https://doi.org/10.1155/ 2015/525218

17. Meng Q, Guo T, Li G, et al. Dietary resveratrol improves antioxidant status of sows and piglets and regulates antioxidant gene expression in placenta by Keap1-Nrf2 pathway and Sirt1. J Anim Sci Biotechnol 2018;9:34. https:/doi.org/ 10.1186/s40104-018-0248-y

18. Zhao Y, Flowers WL, Saraiva A, Yeum K-J, Kim SW. Effect of social ranks and gestation housing systems on oxidative stress status, reproductive performance, and immune status of sows. J Anim Sci 2013;91:5848-58. https://doi.org/10.2527/ jas.2013-6388

19. Schenk S, Saberi M, Olefsky JM. Insulin sensitivity: modulation by nutrients and inflammation. J Clin Invest 2008;118: 2992-3002. https://doi.org/10.1172/JCI34260

20. Mosnier E, Le Floc'h N, Etienne M, Ramaekers P, Seve B, Pere MC. Reduced feed intake of lactating primiparous sows is associated with increased insulin resistance during the peripartum period and is not modified through supplementation with dietary tryptophan. J Anim Sci 2013;88:612-25. https://doi.org/10.2527/jas.2008-1768

21. Koketsu Y, Dial GD, Pettigrew JE, King VL. Feed intake pattern during lactation and subsequent reproductive performance of sows. J Anim Sci 1996;74:2875-84. https://doi.org/10.2527/ 1996.74122875x

22. Borges VF, Bernardi ML, Bortolozzo FP, Wentz I. Risk factors for stillbirth and foetal mummification in four Brazilian swine herds. Prev Vet Med 2005;70:165-76. https://doi.org/ 10.1016/j.prevetmed.2005.03.003

23. Shen Y, Wan H, Zhu J, et al. Fish oil and olive oil supplementation in late pregnancy and lactation differentially affect oxidative stress and inflammation in sows and piglets. Lipids 2015;50:647-58. https://doi.org/10.1007/s11745-015-4024-X

24. Wang H, Ji Y, Yin C, et al. Differential analysis of gut microbiota correlated with oxidative stress in sows with high or low litter performance during lactation. Front Microbiol 2018;9:1665. https://doi.org/10.3389/fmicb.2018.01665

25. Przybylska J, Albera E, Kankofer M. Antioxidants in bovine colostrum. Reprod Domest Anim 2007;42:402-9. https:/doi. org/10.1111/j.1439-0531.2006.00799.x

26. Chen J, Han JH, Guan WT, et al. Selenium and vitamin E in sow diets: II. Effect on selenium status and antioxidant status of the progeny. Anim Feed Sci Technol 2016;21:101-10. https:// doi.org/10.1016/j.anifeedsci.2016.08.021

27. Blaut M. Relationship of prebiotics and food to intestinal microflora. Eur J Nutr 2002;41:i11-6. https://doi.org/10.1007/ s00394-002-1102-7

28. Patel T, Gores GJ. Apoptosis and hepatobiliary disease. Hepatology 1995;21:1725-41. https://doi.org/10.1002/hep.18402 10635

29. Buttle MT, Sandstrom PA. Oxidative stress as a mediator of apoptosis. Immunol Today 1994;15:7-10. https://doi.org/10. 1016/0167-5699(94)90018-3

30. Wang X. The expanding role of mitochondria in apoptosis. Genes Dev 2001;15:2922-33.

31. Kumar S, Vaux DL. A cinderella caspase takes center stage. Science 2002;297:1290-1. https://doi.org/10.1126/science. 1076118

32. Nagata S. Apoptosis by death factor. Ce11 1997;88:355-65. https://doi.org/10.1016/S0092-8674(00)81874-7

33. Neuzil J, Wang X, Dong L, Low P, Ralph SJ. Molecular mechanism of 'mitocan'-induced apoptosis in cancer cells epitomizes the multiple roles of reactive oxygen species and Bcl-2 family proteins. FEBS Lett 2006;580:5125-9. https:// doi.org/10.1016/j.febslet.2006.05.072

34. Adams JM, Cory S. Bcl-2-regulated apoptosis: mechanism and therapeutic potential. Curr Opin Immunol 2007;19:48896. https://doi.org/10.1016/j.coi.2007.05.004 